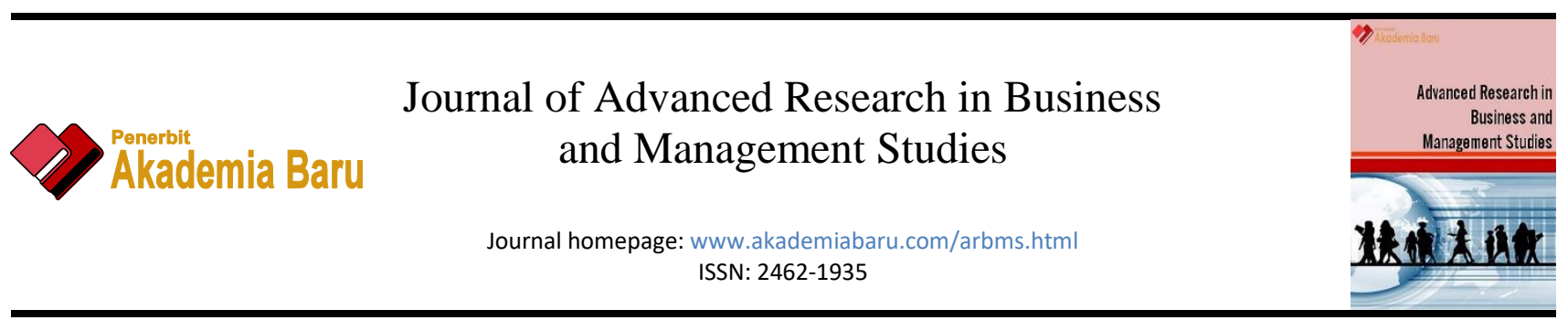

\title{
Sustainability and Competencies of Local Vendors in Maritime Defense Industries
}

\author{
Muhammad Fauzi Abdul Kadir ${ }^{1, *}$, Rahayu Tasnim ${ }^{1}$ \\ 1 Management of Technology, Malaysia Japan International Institute of Technology (MJIIT), University Technology of Malaysia, Kuala Lumpur, \\ Malaysia
}

\section{ABSTRACT}

The survival of the economic well-being of Malaysia is very much dependent on seaborne trade and maritime resources, and these elements are treated as national strategic interests and maritime strategic values. All these values and areas of interest must be protected and safeguarded from any maritime issues and potential threats that can affect Malaysia. This objective can only be achieved if this country has a capable and credible assets or platform for enforcement activities, and reliable, sustainable and competent maritime defence industries which involving shipyards, local vendors, and subsequently supported by other stakeholders. Thus, the development of local vendors in the maritime defence industries is vital for Malaysia. Therefore, this research is about analysing the importance of having sustainable and competent local vendors for the industry; hence proposing a new framework to develop and create more sustainable and competent local vendors. This research has adopted qualitative method, and focuses on Boustead Naval Shipyard (BNS) as Anchor Company and its local vendors as a case study, and data collection processes through interview, observation and document review, and NVIVO as a tool to mapping up the data compilation. With the implementation of new Vendor Development Program (VDP) framework, it has successfully created more sustainable and competent local vendors for the industry, and this effort must be continued. Failure in implementing this initiative effectively will affect the Government aspiration and policy related to National VDP agenda and the concept of Self-Reliance as required by National Defence Policy (NDP).

\section{Keywords:}

local vendors; sustainable and

competency; maritime defense industry; VDP; self-reliance

Copyright @ 2020 PENERBIT AKADEMIA BARU - All rights reserved

\section{Introduction}

As a maritime nation, Malaysia is strategically located at the busiest waterways in the world, and its coastline is spanning to almost 4,492 kilometres, and its territorial waters covers an area of 598,540 kilometres squares including its Exclusive Economic Zone (EEZ). Malaysia relies heavily on oil and gas, shipping, fishing and tourism industries as a major wealth contributor to the nation [30]. Besides that, numerous submarines cables also traversed at the seabed linking the littoral states i.e. between Peninsular Malaysia and Sabah/Sarawak with the international communication centre and networks such as SEACOM cables, ASEAN cables and East-West cables [14]. In the aspect of maritime issues and threats such as maritime terrorism, piracy, overlapping claims, smuggling, drug trafficking,

\footnotetext{
* Corresponding author.

E-mail address: fauzi1681@gmail.com
}

https://doi.org/10.37934/arbms.20.1.1427 
maritime pollution, illegal immigrant and illegal fishing; these issues are becoming more significant and ominous security which affect the survivability of national resources, and subsequently could also jeopardise the sovereignty, stability and security of the nation [15]. In the Royal Malaysia Navy (RMN) Memoir 80 years of serving the nation - 'Defining Moments' dated 27 April 2014, previous Deputy Prime Minister cum Defence Minister (2007), Najib Razak has quoted that, "Malaysia is a maritime nation because of its geographical position and supported by the fact that Peninsular Malaysia is separated from Sabah and Sarawak by South China Sea. Its maritime territory spans twice the size of its land territory. The nation's strategic assets which include islands, off-shore stations and oil rigs worth billions of ringgit as well as the 12 nautical miles of territorial waters, need to be safeguarded and protected always" [23].

Basically, the survival of the economic well-being of Malaysia is very much dependent on seaborne trade and maritime resources, and these elements are treated as national strategic interests and maritime strategic values. All these values and areas of interest must be protected and safeguarded from any maritime issues and potential threats that can affect the nation. This initiative can only be achieved if this country readily equipped with capable and credible assets or platform, reliable maritime defence industries which include shipyards, sustainable and competent local vendors, and subsequently supported by other related stakeholders such as the RMN as main client, MINDEF and Ministry of International Trade and Industry (MITI). Therefore, the development of sustainable and competent local vendors for maritime defence industries is vital for Malaysia. This effort is in line with the concept of self-reliance as stipulated in National Defence Policy (NDP), and the Government national agenda of Vendor Development Program (VDP). Currently, there was no specific and comprehensive maritime defence plan to enhance and develop sustainable and competent local vendors, particularly in manufacturing and servicing related areas. Thus, this industry has yet to have a pool of sufficient sustainable and competent local vendors to manage the activities related to shipbuilding and ship repair. Hence, for the acquisition and servicing of sophisticated and high technology equipment and systems, Malaysia still depends on foreign companies, and foreign Original Equipment Manufacturers (OEMs) to equip and service its armed forces including the RMN. Even, the Government had embarked the transfer of technology and Offset program, but these program not meeting the objective [31].

Due to uncertainty of global economy and commodity, the defence budget has been reduced. The Government orders and investment in defence are slowly decreasing, and it currently also affects the shipbuilding and ship repair budget, and restricts the activities of local vendors, and it has jeopardised the sustainability and competencies of local vendors in maritime defence industries [5]. Thus, the related local vendors are encouraged to identify and explore new businesses in other sectors by diversifying their competency or specialization, in order to ensure their presence in the industry is continued and relevant. Hence, the objective of this research is to analyse and evaluate the importance of having sustainable and competent local vendors for the industry; and subsequently to propose a new framework to supplement and create more sustainable and competent local vendors for the industry. The new VDP framework was introduced in 2014, and it was implemented in 2015. This framework is designed to develop more systematic selection process of local vendors and nurture them whilst in the VDP scheme. This effort is also involved other related stakeholders namely BNS as Anchor Company, the Government such as MITI and MINDEF, and local vendors as main subject of the research. The selection process which involved active registered vendors of BNS. The list of local vendors was retrieved from vendor database of the I-MARS system, and focusing only on local vendors of having critical disciplines of shipbuilding and ship repair activities i.e. engineering and high technology. 


\section{Literature Review}

The understanding of related terminologies, Government perspectives and scholars' views on this subject are equally importance in producing comprehensive and quality research paper.

\subsection{Vendor and Vendor Development Program (VDP)}

BNS has defined vendor as, 'companies or any legitimate entities who are duly registered pursuing business interests with BNS either as a supplier of products or a service providers/subcontractors or a combination of both' $[5,6]$. Hence, vendors in maritime defence industry represents a company who being selected and participated to support the industry either in the form of suppliers or service providers. In the context of VDP vendors, MITI defined these vendors as, 'bumiputera companies registered with MITI under VDP which involved in manufacturing and servicing of engineering and technology' [21]. In relation to VDP, MINDEF has introduced a new guideline or program, known as Economic Empowerment Program (EEP) which encompassed of the element of VDP. This program is designed to fulfil Government's aspiration in developing local defence capabilities through the enhancement of sustainability and competency of local vendors including VDP vendors. This effort is aimed to strengthen Malaysia's defence industry and strategic technological development in fulfilling the concept of self-reliance via providing skilled workforce in high technology, enhancing economic networking development, strengthening vendor development program, and maximizing the usage of localization or local contents, technology transfer and offsets program in relation to the enhancement of national efficiency, competency and competitiveness [18]. MINDEF stresses that this program is to be read in line with MITI National VDP Guideline. Putrajaya Committee on GLC High Performance (PCG), an agency under Prime Minister Department and the process owner of The Red Book (Procurement Guidelines and Best Practices) has also stressed the commitment required from GLCs in materializing this initiative. The achievement of PETRONAS, TM and TNB in developing local vendors were used as the benchmarking. Also highlighted, the Government objective to promote the use of competitive local content, ensuring equal equity share of bumiputera vendors in the nation's economic growth, and develop the capabilities of bumiputera vendors [25].

\subsection{Maritime Defense Industry}

In Malaysian context, the researcher has defined maritime industry covers a very wide spectrum of activities such as shipbuilding and ship repair, port services, maritime defence and law enforcement, ocean and coastal shipping, marine mining, offshore and inland fishing, maritime tourism, marine environment, marine product and services, marine professional services and government authorities and marine or maritime associations which have the potential to grow. Therefore, maritime defence industry is encompassed of all maritime activities related to defence industry, particularly the activities which involved RMN as a key player and major stakeholder, and client to the industry. This activity include the roles played by the shipyards, local and foreign OEMs, local vendors (vendors supporting maritime defence industries, local partner or local agents to foreign OEMs) and related government agencies which involved in carrying out the repair work, servicing, maintenance and refurbishment of all RMNs' ships and equipment such as electronic sensors, weapons, engines and generators, weapon control systems, command and control systems [31]. Other author stresses that maritime defence industry shall encompassed of activities of maintenance, repair and overhaul (MRO) and type of work to more sophisticated jobs involving 
design, manufacturing, and sub-assemblies and through life support of defence assets, systems and equipment [26].

\subsection{National Defense Policy (NDP)}

NDP is an official document guides the Government on how to protect the nation and its area of interests from any threats or aggressors. This document was produced by the Ministry of Defence (MINDEF) with supervision and collaboration of National Security Council (NSC) and other related agencies in 2005, and it was reviewed in 2010. As stipulated in NDP, its objective is to safeguard and defend its national interests - sovereignty, territorial integrity and economic well-being. The national interests that specifically refer to maritime security are as follows:

a. Core area that covers Malaysia's territory, its territorial waters and the airspace above them.

b. Offshore economic interests in its Economic Exclusive Zone (EEZ) and Continental Shelf and surrounding it.

c. Strategic waterways and airspace which consist of the following:

(1) Sea lanes and airspace connecting Peninsular Malaysia and Sabah and Sarawak. Any disruption to these lanes would pose a threat to Malaysia's territorial integrity.

(2) Straits of Malacca (inclusive of its approaches) and Straits of Singapore (and its approaches).

The objective of NDP requires a comprehensive strategy with also encompasses of the guiding principles of self-reliance, total defence, bilateralism and multilateralism. As tabulated in NDP, defence industry is the main contributor for the procurement of high technology and armament systems, and provides the structure for sustainability of services and supports activities. With the high achievement in local defence industry, it shall reduce interdependency of the industry toward foreign OEMs and companies, hence, it shall create more job opportunities for locals, better currency exchange, enhance technology transfer and FDI, and establish downstream activities in other sectors [19].

\subsection{Self-Reliance}

Self-reliance as stated in the NDP means the ability to act independently without foreign assistance to deal with internal security matters, and the ability to act independently to protect its territorial integrity and security interest from low and medium level external threats' $[19,20]$. It covers the ability to provide logistic support for internal military operations. In line with this requirement, maritime defence industries must be strengthen particularly in the aspect of shipbuilding and ship repair, and maintenance, repair and overhaul (MRO) of the RMN's equipment and asset, and subsequently enhances the state of readiness of RMN's fleet. As promulgated in Maritime Defence Doctrine (MDD), self-reliance in maritime defence shall include the following:

a. Ability to deal with medium level conflict.

b. Ability to carry out maritime operation such as:

(1) Continuous monitoring, safeguard and surveillance of national waters.

(2) Protection of offshore stations and installations.

(3) Ability to protect Sea Lanes of Communications (SLOC) and maritime resources 
such as hydrocarbon and fishery.

(4) Ability to enforce maritime law within own jurisdiction.

(5) Ability to control and deter from any outside intrusion of illegal immigrant and subversive elements.

c. Ability to carry out the maintenance and MRO of own assets.

d. Ability to produce spare parts and military high technology equipment [24].

Para $\mathrm{c}$ and $\mathrm{d}$ above is very much related to this research, and the implementation of the concept of self-reliance which clearly connected to maritime defence industries; and it has an impact to the Malaysia's Defence Strategy. In article titled, 'Evaluating the Role of Offsets in Creating a Sustainable Defence Industrial Base: The Case of Malaysia', Kogila, discusses on the understanding of offsets program and the scenario of Malaysian defence industry, and obstacles on the road to defenceindustrial sustainability. She also discussed on the two prong of strategy such as the development of defence industrial base that will be able to support Malaysian Armed Forces (MAF) to attain a certain degree of self-reliance; and development of Malaysia's high technology sectors [17].

\subsection{Sustainability and Competency}

The understanding of sustainability and competency are also important in analysing the issues of this research. As such, Oxford English Living Dictionaries defines 'competence' as 'the ability to do something successfully and efficiently' (http://en.oxforddictionaries.com).For this research, researcher defines competency as, 'a strong point of the vendors in term of skill and knowledge required for maritime defence activities in which the vendors would be able to compete with their competitors'. Sustainability is defined as, 'to maintain or prolong, or capable of being maintained at a steady level without exhausting resources or causing severe damage' [10]. In this context, sustainability of vendors relates to the ability of vendors to sustain and continue to exist in term of capability and competency, survivability, financially sound and committed not only in maritime defence industry but also in other industries. Stephen Bickell stated that sustainability issues in the built environment profession as well a growing focus on using technical skills to provide sustainability solutions. This subject has increasingly come to fore at a strategic level within organization [2]. In fulfilling the needs of the globally potential SMEs, BNS has developed the full capability of vendor program to sustain economic growth and activity that includes the Blue Print by BHIC in creating and designing vendor development program to work with SME in shipbuilding and repair industry. And this situation shall provide the opportunities to strengthen their technical skills and enhance their capabilities [27]. Both terminologies i.e. sustainability and competency are equally important elements, and should be transmitted to all stakeholders in ensuring the survivability of this industry particularly for BNS and its vendors.

\section{Methodology}

BNS as a shipyard and Anchor Company for its local vendors are the subject for this research. This research applied qualitative method with participation of selected local vendors, BNS's management and staff from Vendor Development Management (VDM), Group Supply Chain Management (GSCM), Procurement, Finance and Production Department. It also shall include collaboration with related Government Agencies particularly MITI, Technical Agencies and other Government Linked Companies (GLC) namely Petronas, Sime Darby, Telekom Malaysia (TM) and Tenaga Nasional (TNB). The researcher being the Head of VDM is directly involved in the existing business process and 
activities which issues are perceived and studied. Triangulation data concept was used in this study. For this case, triangulation data is defined as a combination of similarity of phenomena in a method, and a method metaphor can also be described as a triangulation. The triangles talk about the methods of convergence and generally produce more objective information about effective outcomes. Triangulation of data shall be done from data that collected through multiple sources to include interviews, observations and document analysis [11].

\subsection{Interview Approach}

The interviews were conducted using structured and semi-structured questionnaires. Semistructured interviews are also an option because this interview processes are not very strict, unlike the structured interview. In a semi-structured interview, the purpose is to explore the subject matter in the context of a free model and allow respondents to comment on their opinions and thoughts on their own experiences. Researchers need to pay careful attention to the participants' responses and follow their directions in using semi-structured interviews $[12,13]$. The interviewees and respondents are encompassed of various level of management such as Managing Directors (MD), Chief Executive Officer (CEO) and Directors, Senior and Middle Management Team (General Manager, Senior Manager and Manager) and Head of Department from vendors, GLCs and Boustead Heavy Industries Corporation (BHIC) Subsidiaries (as shown in Table 1).

Table 1

The interviewees and respondents

\begin{tabular}{|c|c|c|c|c|}
\hline Managerial Levels & $\begin{array}{c}\text { BHIC } \\
\text { Subsidiaries }\end{array}$ & GLCs & Vendors & Total \\
\hline MDs, CEOs and Directors & - & - & 9 & 9 \\
\hline \multicolumn{5}{|c|}{ Senior and Middle Management } \\
\hline Team & 6 & - & 50 & 56 \\
\hline Head of SCM and VDM & - & 4 & - & 4 \\
\hline \multicolumn{4}{|c|}{ Total } & 69 \\
\hline
\end{tabular}

\subsection{Observation}

Meetings, discussions, brainstorming and presentation cycles are frequent in the use of Action Research cycles. In doing so, the observation, response, judgment and intervention (ORJ) framework becomes the guideline. Coghlan and Shani [9] notes that this method in which researchers may reflect the basis of their experiences, cognition, judgment and ORJI role. Another scholar has created a model directly related to observation with a purpose of bringing attention to emotions and reactions generated from observations [8]. In this case, the researcher is frequently involved in the meetings, workshop and discussion related to VDP issues, award of works or projects to the local and foreign vendors for shipbuilding and ship repair activities i.e. MRO, and the establishment of the new VDP framework on how to develop vendors so that they shall more capable, sustainable and competent in carry out the entrusted jobs. 


\subsection{Document Review}

Some of the collected documents with unclassified information and a few documents with classified security classification were reviewed for the research. The comparison between the written document and the actual process was validated at this stage. This role shall be more accurate in triangular data analysis. The importance of examining written texts and any artifacts is that they are authentic evidence and exist in such a way that different spoken languages are physically persistent and therefore can be separated in space and time [1]. Document clustering techniques are widely recognized as a useful information tool for reorganizing data and information [16] in documents that are mined and collected. There are various ways to compile and review all of the information in particular that has been recorded, as indicated by previous researchers. In this study, all the information were summarized in a single folder, using a simple process of collecting all the relevant files, and then viewing them one by one. Next, the process of analyzing all the information that has been collected in one folder shall be facilitated by the use of NVIVO software.

\subsection{Data Analysis Procedure}

Data analysis procedures are started when the collected data from various sources were converted into transcribed form. This includes interview information from audio tapes, notes, etc. Thereafter, the data reduction process begins with the reading and re-reading of the transcribed data. Next, identifying the emerging themes was carried out upon reading of each transcript during the reduction process. The files were placed in the same folder to ease the process of analysis. Subsequently the open coding procedure was initiated to identify the emerging themes. Upon identification, the theme was separated accordingly in order to avoid any misplacing of information in the system. According to Creswell, there are six step of analysis processes, namely, the analysis in linear order as the cognitive operation is not simply static; organize and set up the data for analysis; read through the data; detailed analysis with coding process; coding process to get a description of the scene or people as well as categories of the data for analysis; and advance how the description of the compositions were interpreted in the qualitative narrative and interpret the significance of the data [11].

For compilation and data analysis, researcher is required to gather and review all information from audio records and interview documents, and feedback of structured questionnaires then transfer all the information into a single transcript document. Then, read through the data. The next important step is to discover the overall meaning in the information to achieve a general sense of the ideas and information given by the participants. A detailed analysis begins with the coding process. Then, all information was organized into categories and labelling all information with conditions by referring to the information given in the interview sessions. For this purpose, the researcher has applied NVIVO 10 as a tool to mapping up and analyze the collection data, and the coding process shall describe the categories for analysis. In this research analysis, the codes were generated for all the information and categories, and subsequently it was analyzed in a general description in NVIVO 10. As a Qualitative Data Analysis application, NVIVO 10 requires knowledgeable skills to attain maximum accuracy out of the research findings. However, learning how to leverage from NVIVO 10 was made easy with the tutorials that were packaged with the software while workshops and trainings were readily provided for a more impressive outcome through using special techniques [29]. 


\subsection{Execution of the Framework}

For this research, researcher has identified two methods or approaches on how sustainability and competency of local vendors could be enhanced and improved i.e. the establishment of new VDP framework and diversification of businesses and competencies of vendors. After a series of meeting and discussion since 2013, the new VDP framework was established in 2014, and fully implemented in 2015. This framework was developed by a team of Group SCM and VDM of Boustead Heavy Industries Corporation (BHIC) with collaboration and supported by other departments of BNS such as Ship Repair and its Project Management Team (PMT), Procurement, Production, Finance and Quality Assurance and Quality Control (QAQC). The researcher, being as one of the key player of the project is directly involved in testing the effectiveness of this framework. For this project, the selection of vendors shall be at random, and it was identified from vendor database of the I-MARS system which is encompassed of vendors from various and multi disciplines or specializations related to engineering and high technology activities. This selection is also based on their track record and performance with BNS, and focuses on quality of their products or services, time of delivery or completion and competitive pricing. As I-MARS system is dedicated system opted by BNS and rented from MARS International, it is used to manage all data related to E-Procurement, E-Human Resources Management (HRM), financial and value of business transaction between BNS and its vendors. This system is also managing and maintaining the vendor E-Assessment which include track record and the performance of all registered and active vendors.

\section{FOR SPECIFIC AREAS OF NEED (TO-BE)}

BUSINESS AS USUAL (AS-IS)

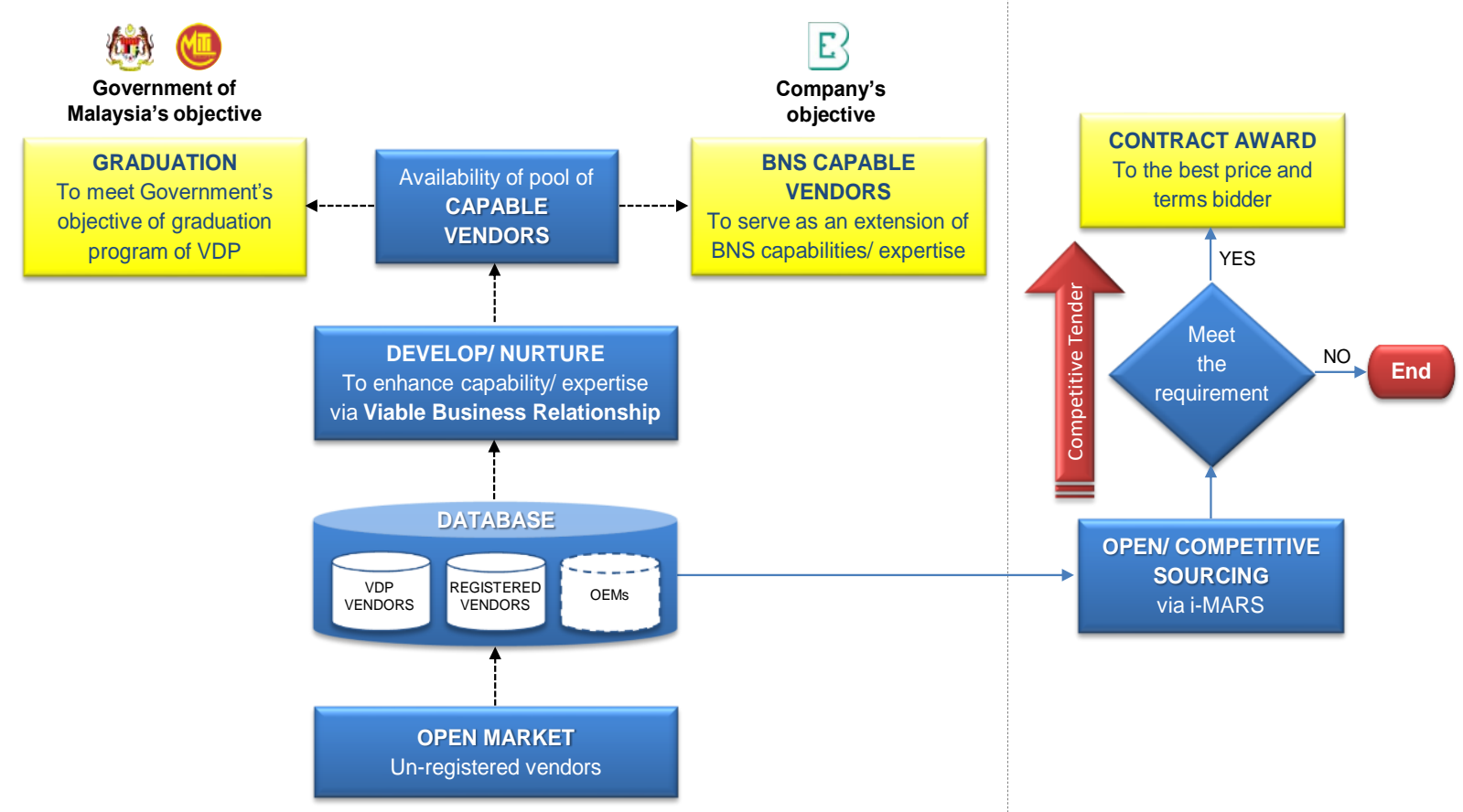

Fig. 1. New VDP Framework 
As shown in Figure 1, for VDP purposes, the process begun with the selection of related vendors from a pool of registered local vendors of BNS. As mentioned earlier, this selection is based on their track record and performance especially on critical specializations related to engineering and high technology namely Combat Management System (CMS), Integrated Navigation System (INS), Integrated Communication System (ICS), piping system, Heating, Ventilation, Air Conditioning (HVAC) system, accommodation and internal fittings, hull structure, propulsion and shafting, electrical system and blasting \& painting which directly involved in shipbuilding and ship repair activities. In this case, trading vendors or common suppliers are not included. After screening through the IMARS, the potential local vendors shall be audited by the appointed audit team. Usually, the audit team shall carried out commercial and technical evaluation which covers physical audit on vendors' related documents such as company profile, list and number of workers, financial audit report, licenses, certification and international standard or classification i.e. Bureau Veritas (BV), Lloyd Register (LR), Germanize Lloyd (GL), and premises including office, workshop and tool and equipment. Upon completion of the audit and evaluation processes, a proposal was prepared and submitted to the top management of holding company i.e. BHIC for approval, and some of selected vendors shall be extended to Government i.e. MITI for consideration to be part of national VDP member. So far, thirty two (32) vendors of BNS were selected for MITI VDP scheme. All selected vendors were closely monitored and tied up with BNS through 'framework agreement' where the selected vendors have to agree with certain mutual term and condition. A part of it commitment to develop and nurture them, BNS is obligated to award continuous works or projects in ensuring their sustainability and competency being enhanced. Their performance have also been assessed and monitored regularly by the end users such as production and PMT, VDM, GSCM, Procurement and Finance Department.

Whilst these vendors in the program, BNS is also obligated to organize continuous competency enhancement training via collaboration with $\mathrm{MITI}$ and its technical agencies namely Malaysia Production Corporation (MPC), SIRIM, Technology Park Malaysia (TPM) and etc. This effort shall include soft skill training such as Project Management Professional, Lean Management, 5S, business Coaching Mentoring, Entrepreneurial skill, and hard skill training such as basic and advanced welding, and welding inspector. These efforts have showed positive impact in enhancing their competencies of skill and knowledge know-how. The success of this program i.e. creating more sustainable and competent local vendors, was measured from graduation initiative, recognition, benefits and awards i.e. Government grant, which received by performed vendors from the related authority. As such, all performed and competent VDP vendors shall be graduated from the program as to meet Government objective of vendor's graduation program, and the vendors are expected to be more reliable and capable so that they able to compete and sustain their presence in the open market. For BNS, these vendors were treated as preferred vendors and later as strategic partners where they could enjoy certain benefits such as direct negotiation and closed tender for specific job related to their specialization. Unlike to vendors outside the program, they have to compete in open tender, and once contract awarded they have to offer competitive pricing with term bidder and certain term and condition. For the diversification, the senior and middle management team of fifty (50) vendors and six (60 BHIC subsidiaries were interviewed to identify the status of their sustainability and competencies enhancement, and it was carried out in 2018.

\section{Results}

Since the execution of New VDP Framework in 2014/2015, this effort has charted tremendous improvement in term of vendor's sustainability and competency enhancement. This achievement 
was measured through recognition on excellence performance of related local vendors by the Government via MITI and other stakeholders, benefits and award of capability and competency enhancement training grant, and Research \& Development and Commercialization (R \& D \& C) grant. For example, from year 2014 till 2018, BNS had managed to secure more than RM400,000.00 of enhancement training grant for its local and VDP vendors, amongst the highest as compared to other Anchor Companies or GLCs. In 2017, a VDP vendor namely AANS Technical \& Services has received 'Industrial Excellence Award for year 2016', and another two (2) of VDP vendors namely Swis Resources and Daya $\mathrm{OCl}$ were recognized and awarded with 'National Champion Award for year 2017' by the Government (BHIC, 2018). And, subsequently followed by another two vendors namely $\mathrm{HH}$ Tech Engineering and Regal Pac were also approved by BHIC/BNS Top Management for submission to MITI for National Champion for year 2018 (VDM, 2018). In line with the excellence performance, two (2) of the VDP vendors were also received and awarded with $R \& D$ \& $C$ grant i.e. AANS Technical \& Services was given RM500,000.00 for the innovation of couplings for piping system in 2017, and Daya OCI has received RM350,000.00 for the innovation on portable HVAC for LCS in 2018. At the same time, as approved by the top management, BNS had graduated four (4) of its VDP vendors namely Daya OCl, HH Tech Engineering, Regal Pac and Mega Idea Engineering in 2017/2018 (VDM, 2018). In other aspect, as stated in I-MARS system, many local vendors either VDP vendors or non-VDP vendors had also managed to secure more than 2.5 billion of Ringgit Malaysia for works and contracts in LCS project, and this news another good sign of the effectiveness of the new VDP framework. The above achievement shows that the recognition and commitment of BNS on the capability and competencies enhancement of local vendors where they were given opportunity to participate in this prestige and unique project as part of developing and creating more sustainable and competent local vendors for the industry. In ensuring this initiative being transformed to a successful agenda, collaboration, cooperation and commitment from other stakeholders namely the Government such as MITI, MINDEF, MOF and RMN are paramount.

As mentioned above, in 2018, the interview session was carried out with the senior and middle management of fifty (50) selected vendors, to identify the level and status of their diversification in relation to their competencies and sustainability. All the above vendors are active registered vendors from various competencies and disciplines have been interviewed and assessed. The following findings has been identified:

a. Twelve (12) vendors started their activities with shipbuilding and ship repair activities (concurrently), namely AANS Technical Services, Micro Precision Engineering \& Services, MS Jaya, Protank Comms, Samudera Selatan Engineering, MTU Services (M) and etc.

b. $\quad$ Sixteen (16) vendors are involved only in ship repair activities such as Regal Pac, Mega Idea Engineering \& Services, Nicetorch, Jurumanjung, OMAHAMS, U.E.C Engineering and etc.

c. Three (3) vendors are participated purely in shipbuilding activities such as RKN Resources, Lumut Waterfront Maritime and Sumber Samudera Engineering.

d. Three (3) vendors are involved in facility management i.e. upgrading and MRO of shipyard's infrastructures, facilities and equipment such as Inno Jati, Jentera Lestari and Growa Crane.

e. $\quad$ Two (2) vendors registered as service providers such as Danamin (M) (fabricator structures for oil and gas activities) and Essem Corporation (MRO provider for oil and gas downstream and upstream activities).

Based on the interview and assessment, only few vendors such as OMAHAMs, Regal Pac, Mega Idea Engineering, Protank Comms, and Nicetorch are still maintaining their existence in ship repair activities. Another fifteen (15) vendors such as Daya OCl, RKN Resources, Sumber Samudera 
Engineering, ZAF Marine and others had diversified their activities and continue their participation with BNS in shipbuilding activities. Small number of vendors, either out of jobs or started exploring in supply and trading activities, or continue their presence and participation in different industry such as power and energy, oil and gas activities and etc. Despite all the challenges, and uncertainty of global economy particularly in oil and gas sector, nineteen (19) vendors such as AANS Technical \& Services, OMAHAMS, Swis Resources, Micro Precision Engineering, MTU Services (M) and few others have put up an effort diversifying their competencies not limited to one client of shipbuilding and ship repair activities. At the same time, they are expanding their businesses to other GLCs such as PETRONAS, Malaysia Marine Heavy Engineering (MMHE) Shipyard, TM and TNB. Their effort are not restricted for domestic market but also they are exploring overseas market such as Middle East, Myanmar, Brunei Darussalam and etc. For example, Micro Precision Engineering \& Services had rendered their MRO services to Royal Brunei Navy Ship.

Surprisingly, out of all vendors above, ten (10) vendors such as Jurumanjung, Mega Idea Engineering, Nicetorch, Regal Pac and JRM Services yet to have any planning to expand or diversify themselves, and they are more comfort within BNS environment. Another twenty six (26) had showed their interests to enhance competencies and diversify their businesses by embarking in other future shipbuilding or construction project of new RMN ships such as $2^{\text {nd }}$ Batch Patrol Vessel, Littoral Mission Ship (LMS) and Multirole Support Ship (MRSS).

The result also showed that thirteen (13) vendors such as Lumut Waterfront Maritime, RKN Shipbuilding Works, Inno Jati Gemilang, Sumber Samudera Engineering and Regal Pac, still maintaining their status quo with single competency, and 100 percent depends on BNS's activity for their major revenue. The remaining vendors had exploring and diversified their businesses with more than one competencies and specialization, and slowly reduce their dependency on BNS. Some of the diversified vendors had already engaged collaboration with foreign suppliers or local and foreign OEMs.

And, all these factors must be taking into consideration whenever managing the above issues. It is a hope that, with the following initiatives, the related vendors shall continue to exist in this challenging industry, and some issues shall be addressed and resolved such as 'waiting time', diversification, competitive pricing and quality of product which some common item could be shared with other industries, thus provide and create continuous job opportunities for vendors, and to the population or society within the surrounding of the industries. One vendor for one product no longer relevant in this presence era, and diversification of product and services for different industries will helps vendors to continue to sustain and survive.

\section{Conclusion}

With the enforcement of this comprehensive and systematic new VDP framework, and the implementation of diversification initiative may benefited both parties i.e. BNS and its vendors. Perhaps, this effort could continue reduces bureaucracy, non-performing vendors, vendor's problem in management and financial, thus, provide competitive pricing, adapted good corporate governance practices and paved away negative attitude of the management team. Despite, this initiative has enhanced sustainability and competencies of vendors local, it also offers better and fair business opportunity, produce quality product and increase profit margin of both parties.

Less dependency of related local vendors on BNS for their major income, it has successfully developed and created more capable, sustainable and competent local vendors in this industry. The effort of maintaining and enhancing the sustainability and competencies of local vendors including bumiputera vendors was one of key elements in ensuring the survivability of the maritime defense 
industry of the nation, hence, attaining the concept of self-reliance as tabulated in NDP. It is also proposed that:

a. The implementation of new VDP framework must be continued for longer period of time.

b. Continue to encourage local vendors to diversify their competency, and embark more than one specialization or discipline, subsequently explore and participate in other industries or sectors for their survivability.

c. Promote less dependency on BNS for their main income, and explore other opportunities.

d. Encourage local vendors to develop and embark collaboration and joint venture initiatives with foreign OEMs, hence, transfer of technology, offset and localization efforts could be materialized.

e. Related stakeholders should also plays their role and committed in ensuring the above objective is achieved.

f. BNS as Anchor Company must continue to assist its local vendors in enhancing their survivability and competency, and promoting and commercialising their products and services via business matching and exploring new networking with OEMs, and other Anchor Companies or GLCs, vendors or players in other industries.

As highlighted above, the development of local vendors' sustainability, capabilities and competencies are also justified to coup up with present and future requirements, and this arrangement must be given a priority. This effort could also be materialized by continuing extending benefits and incentives such as ' $R$ \& $D$ \& $C$ grant, and capability and competency enhancement training grant, despite effort of developing local vendors via VDP Scheme, promote for cooperation and networking with other stakeholders, Anchor Companies, technical agencies and selected financial institutions. Local vendors should also be advised and encouraged to be more persistence and aggressive in adopting collaboration and joint venture initiatives to become a strategic partner to foreign suppliers and manufacturers or foreign OEMs in particular, so that localization, offsets program and technology transfer could be enhanced. Hence, the successful of self-reliance was partly depends on the effectiveness of the conduct and implementation of these initiatives, and this would also ensure the livelihood of the population, the survival, stability and security of the nation being maintained. And, any lacking in support and commitment from BNS, other stakeholders and society would also reflect the failure of the whole nation.

It is also hopes that this research could supplement the decision makers in making wise and right decision for the betterment of the industry, and as a guideline for other Anchor Companies or GLCs or other industry players in developing and creating their sustainable and competent local vendors for their industries. As contribution to the society, BNS is always mindful and novel of its role and commitment in assisting the Government's aspiration to spur economic growth and nurture the development of local vendors particularly SMEs including bumiputera vendors via VDP scheme, and the implementation of New VDP Framework and diversification initiatives; thus assisting them in enhancing their sustainability and competency to compete in this challenging era. As mentioned earlier, this program is also aimed to upholding the Government's VDP initiative as well as Bumiputera Empowerment Agenda (BEA) as part of Economic Transformation Program (ETP) which is closely monitored by the Government particularly MITI and MOF. As commitment, BNS has adopted a comprehensive and multi-pronged approach in its VDP and BEA covering various initiatives such as organising and coordinating capability and competency enhancement training, technical and financial advisory, promote and assist in business matching and networking with local and foreign OEMs, and other industry players as part of developing local vendors for the industry. This stands testimony is clear commitment towards supporting Government policies and agenda particularly in 
nurturing sustainable, reliable, competitive and competent local vendors as to attain self-reliance in the maritime defence industry.

\section{Acknowledgement}

This research is funded by the Ministry of Higher Education (MOHE) under the Industrial PhD program of MyBrain15 with collaboration from Boustead Naval Shipyard (BNS) and Universiti Teknologi Malaysia (UTM). The author or researcher extends his sincere appreciation to the supervisors and reviewers for their comments and guidance, and also wishes to thank all related parties that involved in this research. The author or researcher takes responsibility for any typographical errors that went through unnoticed.

\section{References}

[1] Ahuja, Renu. "Towards an Understanding of Excellence in Urban Pedagogy: A Portrait of a High School." Qualitative Report 12, no. 1 (2007): 1-19.

[2] Bickell, S. "Defining a profession: core competencies for sustainability." The College of Estate Management paper (2013).

[3] BHIC. (2017). Annual Report 2016: Driven by Resilience Ahead. Kuala Lumpur: Boustead Heavy Industries Corporation Berhad, Menara Boustead.

[4] BHIC. (2018). BHIC Annual Report 2017: New Heights of Excellence. Kuala Lumpur: Boustead Heavy Industries Corporation, Menara Boustead, p 49.

[5] BNS (2015). Yard's Monthly Operation Management Meeting, Arowana Meeting Room, BNS, Lumut, 30 October 2015.

[6] BNS. (2007). Guidelines Vendors and Vendor Development Program. Lumut: Boustead Naval Shipyard. p 2.

[7] BNS. (2013). Procedure for Selection and Graduation of Vendor under VDP Scheme, 6 November 2013. Lumut: Vendor Development Management Department, Boustead Naval Shipyard, $\mathrm{p} 3$.

[8] Cannata, Mary B. "What is the effect of observation by an OD practitioner on the OD practitioner's intended outcome of an OD intervention?." (2013).

[9] Coghlan, David, and A. B. Shani. "The Challenges of the Scholar-Practitioner: Introduction to the Special Issue." The Journal of Applied Behavioral Science 45, no. 1 (2009): 5-7. https://doi.org/10.1177/0021886308328852

[10] Collin English Dictionary. (1998). Glasgow. HarperCollins Publishers, pp 220, 243 \& 1168.

[11] Creswell, John W., and J. David Creswell. Research design: Qualitative, quantitative, and mixed methods approaches. Sage publications, 2017.

[12] Dagbjartsdóttir, Sandra. "Quality Status and Quality Aspects in the Icelandic Construction Industry." PhD diss., 2012.

[13] Dodge, Pamela R. "Managing school behavior: a qualitative case study." (2011).

[14] Fauzi Kadir. (2001). Strategic Situation in South China Sea: A Malaysian Perspective. KDP Journal Vol 10 December 2001, Lumut: Naval Training College, p 43.

[15] Fauzi Kadir. (2004). Malaysian Maritime Defense Industry Towards Achieving Self-Reliance: An Analysis. Kuala Lumpur: Maritime Defense Research Department of Penang Shipbuilding \& Construction, p 1 (Working Paper presented to PSC Top Management Seminar, 24 May 2004, KLGCC, Kuala Lumpur).

[16] Kishida, K. (2003). Techniques of Document Clustering: A Review. Library and Information Science.

[17] Kogila Balakrishnan. (2010). Evaluating the Role of Offsets in Creating a Sustainable Defence Industrial Base: The Case of Malaysia, The Journal of Defence and Security, Vol. 1 No.1

[18] MINDEF. (2011). Guideline for Economic Empowerment Program (EEP). Kuala Lumpur: Defence Industry Division, Minsitry of Defence, 28 January 2011. pp 2 \& 6-8.

[19] MINDEF. (2010). National Defense Policy. Kuala Lumpur: Ministry of Defence (MINDEF). Page 30.

[20] MINDEF. (1994). Malaysia Defence: Towards Defence Self-Reliance. Kuala Lumpur: Policy Division, Ministry of Defence (MINDEF), p 22.

[21] MITI. (2014). Guideline for Vendor Development Program (VDP). Putrajaya: Entrepreneur Development Department, Ministry of International Trade and Industry (MITI), 19 August 2014.

[22] Navy Headquarters. (2014). Tentera Laut Bertaraf Dunia. Samudera 2014 Edisi Khas, Markas Tentera Laut, Kuala Lumpur, pp 10-11 \& 22-25.

[23] Navy Headquarters. (2014). Defining Moments. Kuala Lumpur: Ministry of Defence. 
[24] Navy Headquarters. (2001). Maritime Defence Doctrine (MDD). Kuala Lumpur: Ministry of Defence, p 16.

[25] PCG. (2006). Red Book: Procurement Guidelines and Best Practices. Kuala Lumpur: Putrajaya Committee on GLC High Performance, PETRONAS Twin Towers, pp 38 - 44.

[26] Rashid Hussain. (2008). Evaluating the Effectiveness of Technology Transfer in Application of the Malaysian Defence Industry in the Maritime Section. Bangi: Faculty of Social Science and Humanities, National University of Malaysia, p 63.

[27] Russlan, David, Krishna. (2014). Malaysia Progress 2013 -2014. Kuala Lumpur: Greatmall Print Sdn Bhd, pp 29 - 31 $\& 67-71$.

[28] VDM. (2018). Minutes of Monthly Vendor Development Management Serial VDM/04/2018 - (75) dated 15 September 2018. Lumut: Boustead Heavy Industries Corporation, p 2.

[29] Uzairiah Tobi. (2014). Qualitative Research \& NVIVO 10 Exploration. Kuala Lumpur: Aras Publisher.

[30] Wiedemann, Jan. (2014). The Royal Malaysian Navy: 80 Years of Evolution: Naval Forces Special Issue 2014 Vol. XXXV, Monch Verlagsgesellschaft mbH, Bonn, Germany, p 7.

[31] Yahya Hashim. (2003). Malaysia's Defense Policy: An Analysis of Malaysia's Maritime Industry in Supporting the Concept of Self Reliance. Bangi: Faculty of Social Science and Humanities, National University of Malaysia, pp 2 - 3. 